exposure. The current study estimates the future lung cancer burden due to respirable crystalline silica (RCS) exposure among Ontario construction workers, and assesses the impact of implementing interventions on this burden.

Methods The annual number of new cancer cases attributable to RCS was estimated from 2030 to 2060 using Levin's equation based on the prevalence of exposure (PrE) and the risk of cancer (RR) associated with RCS exposure. The RR was selected from a review of the epidemiologic literature. The PrE was estimated using CAREX Canada's estimates of prevalence and level of exposure, combined with historical and projected employment data, labour force characteristics, and survival probabilities. The intervention methods (personal protective equipment, wet cutting) were assumed to be fully implemented from 2020, and incorporated into the model by adjusting prevalence and level of exposure downwards.

Results We estimated that without intervention, 107 lung cancers would be attributable to RCS exposure in Ontario construction workers in 2030.This number increased to 181 in 2060. If intervention methods were applied, the reduction in the attributable cases became evident from 2040 onward, with a maximum reduction of 51 cancers in 2060. Overall, 481 cancers would be prevented between 2030 and 2060, which is $11 \%$ of the total cases if the interventions were not implemented.

Conclusions Future work-related cancers can be prevented by reducing workers' exposure. Combining the economic assessment of both the cancer burden and the costs of implementing exposure controls will help to assess the cost-benefit of different intervention methods, which can be used to direct intervention strategies in construction workplace.

\section{C.6 EFFECTIVENESS OF AN AUDIT-BASED OCCUPATIONAL HEALTH AND SAFETY MANAGEMENT SYSTEM CERTIFICATION ON FIRM INJURY RATES IN ALBERTA, CANADA} ${ }^{1,2}$ Chris McLeod*, ${ }^{1}$ Robert Macpherson, ${ }^{1}$ Adebayo Aderounmu, ${ }^{3}$ Willianm Quirke,
${ }^{1}$ Mieke Koehoorn. ${ }^{1}$ The University Of British Columbia, Vancouver, Canada; ${ }^{2}$ Institute for
Work and Health, Toronto, Canada; ${ }^{3}$ WorkSafeBC, Richmond, Canada

\subsection{6/OEM-2019-EPI.177}

Objectives To determine if achieving an audit-based occupational health and safety management system certification (OHSMS) is associated with lower firm-level lost-time injury rates.

Methods Firm-level workers' compensation claims and OHSMS audit data were extracted from eligible industry sectors for the years 2000 to 2015. OHSMS and non-OHSMS firms were matched on observable baseline characteristics using coarsened exact matching methods. A difference-in-difference observational research design using population-averaged negative binomial regression models estimated the effect (incidence rate ratios (IRR) with 95\% confidence intervals) of OHSMS certification on firm lost-time injury rates, adjusting for confounders. Models were stratified by industry sector and type of OHSMS (certification for small versus large firms).

Results The cohort included 14,377 OHSMS firms matched to 11338 non-OHSMS firms. Overall, OHSMS certification reduced lost time injuries (IRR: 0.86, 95\% CI: 0.83-0.88), with a greater effect in 2011-15 (IRR: 0.79 , 95\% CI: $0.75-$ 0.82). OHSMS certification was most effective in reducing injuries in the manufacturing (IRR: 0.75 , 95\% CI: $0.70-0.80$ ), trade (IRR: $0.79,95 \% \mathrm{CI}: 0.73-0.86$ ), and transportation
(IRR: 0.80 , 95\% CI: 0.72-0.89) sectors. No effect was found in oil and gas (IRR: 1.05 , 95\% CI 0.91-1.20), business (IRR: 0.89 , 95\% CI: 0.89-1.10) and forestry (IRR: 1.05 , 95\% CI: 0.83-1.33) sectors. OHSMS certification for small firms was not associated with a reduction in injuries (IRR: 0.98, 95\% CI: 0.91-1.06.) in contrast to OHSMS certification for large firms (IRR: 0.84, 95\% CI: 0.82-0.87).

Conclusions OHSMS certification is effective in reducing firm injury rates. Effectiveness varied by sector, time period, and small or large firm certification. Sectoral differences in OHSMS effectiveness suggest that the ability to prevent hazards targeted by certification may vary by work environment. Further, small firm OHSMS certification may not be identifying safer firms.

\section{Health Inequalities}

\section{D.1 INVESTIGATING THE DIFFERENCE OF WORK-RELATED HARMS IN NEW ZEALAND BY ETHNICITY}

Trang Khieu*, Michelle Poland, Kirsten Lovelock. WorSafe New Zealand, Wellington, New Zealand

\subsection{6/OEM-2019-EPI.178}

In New Zealand about $10 \%$ of workers are harmed every year, with approximately 200000 claims made to Accident Compensation Corporation (ACC) to cover the cost of injury and illness. Work-related injury and illness outcomes differ between ethnic groups. Māori (indigenous population) workplace fatality rates are $19 \%$ higher by industry and $10 \%$ higher by occupation than for non-Māori. According to Statistics New Zealand from 2002-2017, Māori were more likely to have higher rates of work-related claims than non-Māori. This study currently underway has used the Integrated Data Infrastructure (IDI) to look at different injury types and explore injury distribution between Māori and non- Māori in terms of age, sex, industry and occupation. WorkSafe applied to Statistics New Zealand (Stats NZ) for access to microdata in the IDI in July 2018 and was granted access in September 2018. In this study, data for people with accepted workrelated ACC claims has been linked to 2013 Census to identify the industry that ACC claimants have worked in and their occupations. This data has then been linked to data on sex, age and ethnicity as recorded for the IDI population. Confidentiality of data in this study has followed Stats NZ's output rules including random rounding to base 3, suppression and aggregation.

\section{D.2 HEALTH-RELATED EDUCATIONAL DIFFERENCES IN DURATION OF WORKING LIFE AND LOSS OF PAID EMPLOYMENT: WORKING LIFE EXPECTANCY IN THE NETHERLANDS}

Alex Burdorf*, Suzan Robroek. Erasmus Mc, Rotterdam, Netherlands

\subsection{6/OEM-2019-EPI.179}

Objectives This study aims to provide insight into healthrelated educational differences in duration of working life by working life expectancy (WLE) and working years lost (WYL) through disability benefits and other non-employment states in the Netherlands. 
Methods Monthly information on employment status of the Dutch population $(n=4,999,947)$ between 16 and 66 year from 2001 to 2015 was used to estimate working life courses. Across educational groups monthly transitions between paid employment and non-employment states were calculated with a Markov model with transitional probabilities. Using this multistate model (R-package mstate) the WLE and WYL due to disability benefits and other nonemployment states were estimated, stratified by educational groups.

Results Despite starting in paid employment much earlier, low educated men and low educated women had a 4.17 (men) and 9.50 (women) years lower WLE at age 16 than high educated men and women. Among low educated men 3.59 WYL were due to disability benefit compared to $0.78 \mathrm{WYL}$ among high educated men, resulting in a WYL gap 2.81 years. Low educated women had 3.47 WYL due to disability benefit compared to 1.38 WYL among high educated women introducing a WYL gap of 2.09. Educational inequalities in premature death added to this WYL gap another 0.7 years among men and 0.3 years among women.

Conclusions The working life course showed large educational differences. A considerable amount of the lost working time is health-related due to disability benefits and premature death. In comparison to high educated workers, those with a low educational level lose a substantial part of their working life due to disability benefit, unemployment, and no income. The metrics of WLE and WYL provide useful insights into the life-course perspective of working careers.

\section{D.3 WORKING CONDITIONS AND HEALTH BEHAVIOUR AS CAUSES OF EDUCATIONAL INEQUALITIES IN SELF- RATED HEALTH: AN INVERSE ODDS WEIGHTING APPROACH}

\begin{abstract}
${ }^{1}$ Jolinda Schram*, ${ }^{1,2}$ Joost Oude Groeniger, ${ }^{1}$ Merel Schuring, ${ }^{3}$ Karin Proper, ${ }^{3}$ Sandra van Oostrom, 'Suzan Robroek, 'Alex Burdorf. 'Erasmus Medical Centre Rotterdam, Department of Public Health, Rotterdam, Netherlands; ${ }^{2}$ Department of Public Administration and Sociology, Erasmus University, Rotterdam, Netherlands; ${ }^{3}$ Centre for Nutrition, Prevention and Health Services, National Institute for Public Health and the Environment (RIVM), Bilthoven, Netherlands
\end{abstract}

\subsection{6/OEM-2019-EPI.180}

Background This study aims to estimate to what extent working conditions and health behaviours mediate the increased risk of low educated workers to report a poor health.

Methods Respondents of the longitudinal Survey of Health, Ageing, and Retirement in Europe (SHARE) in 18 European countries were selected aged between 50 years and 64 years, in paid employment at baseline and with information on education and self-rated health $(n=15,126)$. Health behaviours and physical and psychosocial work characteristics were measured at baseline, while self-rated health was measured at 2 year follow up. We used loglinear regression models and Inverse Odds Weighting causal mediation analysis to estimate the total effect of low education on self-rated health and to decompose the effect into natural direct (NDE) and natural indirect effects (NIE).

Results Lower educated workers were more likely to be in poor health compared to higher educated workers. The total effect of low education on self-rated health was $\mathrm{RR}=1.81$ [95\% CI 1.66-1.97]. For work conditions, having a physical demanding job was the strongest mediator, followed by lack of job control and lack of job rewards. NIE through working conditions was $\mathrm{RR}=1.16$ [95\% CI $1.06-$ 1.25], explaining about $30 \%$ of educational inequalities in self-rated health. For health behaviour, body mass index and alcohol were the strongest mediators, followed by smoking. NIE though health behaviour was $\mathrm{RR}=1.14$ [95\% CI 1.071.20], explaining about $27 \%$ of educational inequalities in self-rated health.

Conclusions Preventive interventions focusing on reducing physical work demands as well as improving health behaviour may contribute to reducing educational inequalities in selfrated health among workers in Europe.

\section{D.4 HEALTH INEQUALITIES AMONG WORKING POPULATION OF LATIN AMERICA AND THE CARIBBEAN}

\begin{abstract}
1,22Michael Silva-Peñaherrera* 1,3,4,5 María Lopez-Ruiz, 1,2Pamela Merino-Salazar, ${ }^{2}$ Antonio Goméz-García, ${ }^{1,3,4}$ Fernando Benavides. 'Center for Research in Occupational Health (CISAL) Universitat Pompeu Fabra (UPF), Barcelona, Barcelona, España; ${ }^{2}$ Research Group on Working Conditions and Occupational Health, International SEK University, Quito, Ecuador; ${ }^{3}$ CIBER Epidemiología y Salud Pública (CIBERESP), España; ${ }^{4}$ MIM (Hospital del Mar Medical Research Institute), Barcelona, España; ${ }^{5}$ Facultad Latinoamericana de Ciencias Sociales, Salamanca, España
\end{abstract}

\subsection{6/OEM-2019-EPI.181}

Background Working and employment conditions are weighty health determinants. Low-income countries are frequently exposed to occupational risks, employment agreements are poorly regulated and a high proportion of the working population are in the informal sector. Studies in Latin American and the Caribbean (LAC) have been hampered by the lack of reliable data available.

Objective To describe and compare the health inequality gap among workers of 20 countries of LAC.

Methods Data have been taken from the last available Working Conditions Survey, National Health Surveys and from official records and national statistical institutes of each country. Three indicators were calculated to estimate health status of the working population (poor-self-perceived health, fatal and non-fatal injuries at work and general mortality within the working-age population), stratified by sex, age, level of study and occupation. Disparity was measured using Keppel index of disparity (ID) and Kuznets relative. Absolute and relative differences were calculated using the best health status country as reference category.

Results Mortality among the working-age population was higher in men and varied from 87.4 deaths per 1000 inhabitants in Chile to over 182.2 in Bolivia. Keppel ID between countries was 0.5 , indicating medium-high disparity. The prevalence of poor self-perceived health was higher in women and revealed a gradient by age, education level and occupation, in which young people in qualified non-manual occupations and high levels of study had lower prevalence. The ID was 0.7 between countries demonstrating high disparity and the range varied from 12.2 in Uruguay to 50.9 in Nicaragua.

Conclusions This study reveals the existence of wide gaps in health among workers in LAC, both within and between countries. The limitations of cross-country comparative data should considered. However, this analysis increases our understanding of the causes of inequalities and provides evidence to establish better public policies. 